\title{
CFD Modeling of Flue Gas Cooler of Oxy Fired Bubbling Fluidized Bed Combustor Using Coal and Biomass
}

\author{
Ravi Inder Singh
}

\begin{abstract}
In many industrial processes hot gas is cooled down before it has been sent to atmosphere. The flue gas is a gas mixture that mainly consists of oxygen, carbon dioxide, water vapor and nitrogen. Additional it may contain sulphur dioxide, nitrogen dio oxide and other marginal species. It usually also contains dust and ashes. While the oxygen content is very much lowered compared to that of ambient air, the content of carbon dioxide can reach a volume fraction of up to twenty five percent. Especially at the modern waste incineration plants the content of water vapor can go up to a few percent.

In this work computational fluid dynamic model is formed for flue gas cooler that are attached in series for $20 \mathrm{~kW}$ Oxy fired Bubbling fluidized bed Combustor Using Coal and Biomass. The model is based on the Lagraingian approach and Discrete Particle Model. The model is solved using commercial Software Ansys Fluent. The geometrical domain is formed in Solid Works. The simulations were performed in Ansys Fluent commercial software. The maximum air flow rate used for this simulation is $80 \mathrm{~kg}$ per hour. The flue gas enters on the side of gas cooler and few particles are entrained in gas cooler. The flue gas is the sucked by ID fan. The flue gas is cooled with the help of $0.5 \mathrm{HP}$ water circulation pump. The pump circulates the water through 0.5 inch pipe line. In order to cool the flue gas down cold water a flow rate of 10-12 litre per minute and temperature of $293 \mathrm{~K}$ is supplied. The velocity, temperature and pressure contours are plotted. The results are also calculated for different types of fuels. The various types of biomass and coal are used in fluidized bed. This leads to variation of ash particles size in flue gas. The particle size in fuel causes the variation in size of ash in flue gas which in turn affects the performance of flue gas cooler. The effect of variation in size of particles on exit flue gas temperature is also investigated.
\end{abstract}

Index Terms - Flue gas cooler, discrete particle model, flow rate, lagrangian approach.

\section{INTRODUCTION}

The problem of designing flue gas cooler is to withstand the highly abrasive nature of flue gas leaving the process chamber, as well as the high temperature. The high degree of gas cleansing before it leaves process equipment demanded today by many of our communities.

Due to high ash content in coal used in fluidized bed units it becomes necessary to add a gas cooling device before the gas exit to atmosphere along with the multi-cyclone collector.

This is done to assure that the exiting flue gases are within the temperature range of 300 to $450 \mathrm{~K}$, with no possibility of even flashes of higher temperatures. The exit temperature of flue gas depends upon the materials of pipe, chamber, and supply of water in the flue gas cooler.

Manuscript received June 14, 2016; revised November 4, 2016.

Ravi Inder Singh is with Birla Institute of Technology and Science-Pilani, Pilani Campus Jhunjhunu, Rajasthan, 333031, India, 00911596515096 (e-mail: dr.rjassar@gmail.com).
Computational Fluid Dynamics (CFD) is a tool increasingly used for the solution of flow related engineering problems. The applications have a broad variety: Simulations in automobile and aerospace industry, biomedical industry, electronics cooling, chemical engineering, turbo machinery, combustion, heat and power generation as well as heat and cold pipes are possible applications.

In the field of combustion CFD is being increasingly used for the optimization of gas combustors and pulverized coal furnaces and numerous types of heat exchangers. The CFD routines developed for biomass based furnaces, heat exchangers and boilers are successfully applied in various cases regarding furnace and boiler development as well as regarding the optimization of existing equipments from small-scale to medium and large scale furnaces and boilers. The development and optimization of biomass grate furnaces via CFD analysis leads to a considerable reduction of investment and operating costs by a heat exchanger design, by an increased availability of the heat exchanger, by reduced fouling as well as by reduced flue gas fluxes in the heat exchanger.

Furthermore, CFD analysis also helps to avoid velocity and temperature peaks in certain heat exchanger which are of special relevance regarding material stress and deposit formation. For high ash fuels additional measures, like ash deposit formation can be investigated with CFD simulation In addition, the influence of particle laden flue gas flow on material stress caused by erosion can also be evaluated using "particle tracking calculations" and considered by material selection or prevented by appropriate modifications of heat exchanger. Actual residence times of flue gas, velocity and temperature are interesting results in flue gas cooler. Finally, CFD simulations lead to an improved understanding of the fundamental physical and chemical processes in the flue gas cooler and, therefore, to a considerably improved design.

In this work computational fluid dynamic model is formed for flue gas cooler that are attached in series for $20 \mathrm{~kW}$ Oxy fired Bubbling fluidized bed Combustor using coal and biomass. The model is based on the Lagraingian approach and Discrete Particle Model. The model is solved using commercial Software Ansys Fluent. The results are validated with measurements from experimental setup.

\section{LITERATURE REVIEW}

Heat exchangers are very important part of energy recovery system of waste to energy plants. Selection of suitable types of heat exchangers represents primary importance in design of these systems. it is necessary to perform the design of heat exchangers with maximum degree of compactness in relation to process parameters like 
temperature, composition of process fluids, proximity to fouling and potential operational problems. Although numerous research papers found on heat exchangers but very few relevant papers are found as flue gas cooling is not required for many of industrial processes.

Viggo [1] discussed the effects of flue gas cooling in power plants. Simon (1995) discussed that the nuclear power station could not be put into operation and decided to erect a thermal power station. They studied about the flue gas desulfurization system. They found that public acceptance could not be reached without sufficient flue gas cleaning systems.

Kvamsdal [2] discussed the results of an activity performed in the ongoing EU project, CESAR. In this project five different baseline power-plants are considered. These consist of two lignite- and two bituminous-coal fired plants while the fifth is fuelled by natural gas. Part of the design work relates to identifying the benefits attainable through appropriate integration of flue-gas cooling to these baseline power-plants. The reductions in capturing of flue gas are basically due to the inclusion of pre-cooling. However, a positive effect of inter-cooling was also found for all the coal cases, while a negative cost effect was found for the natural gas case. For piperazine as solvent the positive effect of cooling was much more pronounced than for MEA and especially the effect of inter-cooling.

Gao and Sun [3] studied the exhaust flue gas cooler in a $300 \mathrm{mw}$ oxy-coal fired boiler. The simulation model of the cooler was established by the method of lumped parameter. The change rule of the exhaust flue gas cooler parameters and the flue gas thermal physical property parameters were analyzed by the disturbance of the coal feeder speed. It is found that, the simulation model of exhaust flue gas cooler was established based on the conservation laws of mass, momemtum and energy. The simulation experiment results show that the change rules of main operational parameters and the flue gas thermal physical property parameters in the exhaust flue gas cooler can be reasonably presented by the model with the speed disturbance of coal feeder, which can be the reference for the design and the operation control of the flue gas coolers.

Nipun [4] discussed the design and performance analyses of condensing heat exchangers for recovering water and waste heat from flue gas. There has been an increasing interest in new technologies to improve the efficiency of coal based thermal power plants and to reduce the consumption of cooling water for cooling towers. This report discusses the opportunities of recovering heat and water from flue gas using condensing heat exchangers. The impact on water condensation efficiency, total heat transfer and total annual cost were analyzed for five different arrangements. The impact of heat exchanger design parameters such as heat exchanger tube diameter and tube transverse pitch was analyzed. Additionally, the prospects of pre cooling the flue gas using water spray and its impact on performance of heat exchanger was also studied.

Samer [5] investigated direct contact condensation for wet flue-gas waste heat recovery using organic rankine cycle. Low-temperature flue gases exiting industrial processes could be recovered for electricity generation and constitute an effective mean to reduce primary energy consumption and carbon dioxide emissions. in the wet flue gases, substantial heat can be recovered if water vapor contained in the gases is condensed. technical options include indirect contact water vapor condensation recovery, where heat is transferred between the two fluids (typically flue gases and working fluid) using an intervening wall (typically fin-and-tube heat exchanger) and direct contact water vapor condensation recovery, which involves direct mixing between flue gases and cooling fluid (typically water) through a condensing unit.

Precise Literature on flue gas cooling has not been found. Detailed literature is proprietary of companies.

\section{DETAILS OF EXPERIMENTAL APPARATUS}

The experimental setup is shown in Fig. 1. The details of this setup is as below. This length of fluidized bed unit is 1.8 $\mathrm{m}$. This is square bubbling fluidized bed combusor made from DST, New Delhi India Grant. This is followed by two cyclones, induced fan, flue gas cooler and stack. The two cylones are used because this unit is designed for mainly high ash coal and biomass. The oxygen can be supplied from bottom and as well from side. But this system works well for other waste also. The net thermal capacity of this system is below $20 \mathrm{~kW}$. The maximum amonut of fuel supplied that can be supplied to this unit is $15 \mathrm{~kg} / \mathrm{hr}$. The test rig is used for experimental validation. Fig. 2 shows the description of flue gas cooler. Fig. 3 shows the actual picture of flue gas cooler. The dimensions and other parameters required for study are given in Table I.

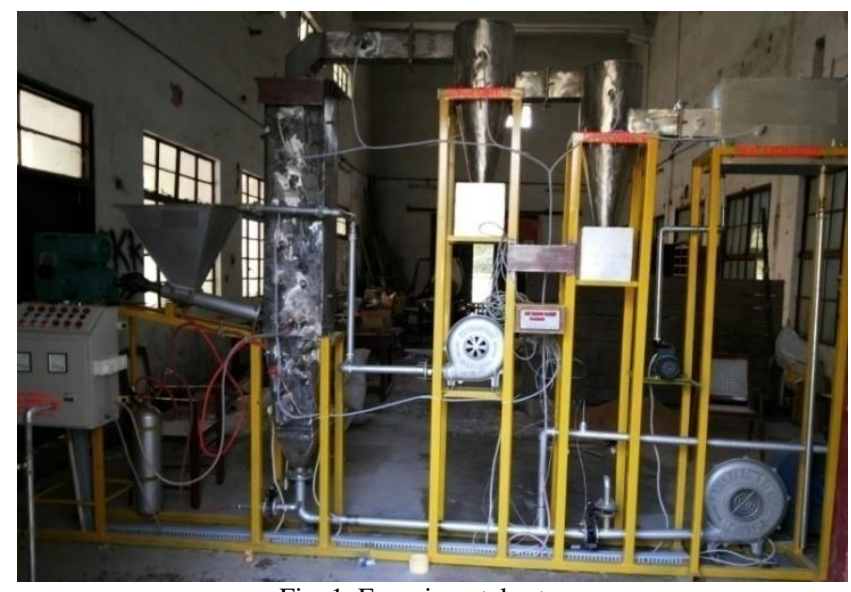

Fig. 1. Experimental setup.

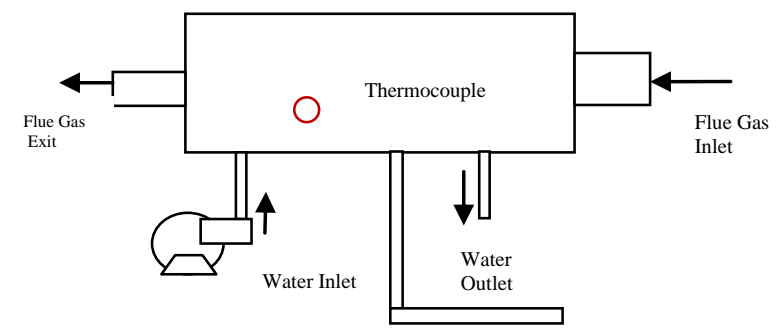

Flue Gas Recycle

Fig. 2. Description of flue gas cooler.

The results are discussed in results and discussion content. The ports $\mathrm{S}$ is used for mesurement of gas concentration. The flue gas is passed through twin cylones. The eighty percentage of ash is entrained through first cylone and 
remaining twenty percentage in second cylone. Fig. 2 also shows the thermocouples which are used for measurment of temeperature. The other ports are also used for measurement of velocities. The velocities of flue gas cooler are measured using Testo $350 \mathrm{XL}$ professional which is purchased through DST, New Delhi, India Grant.

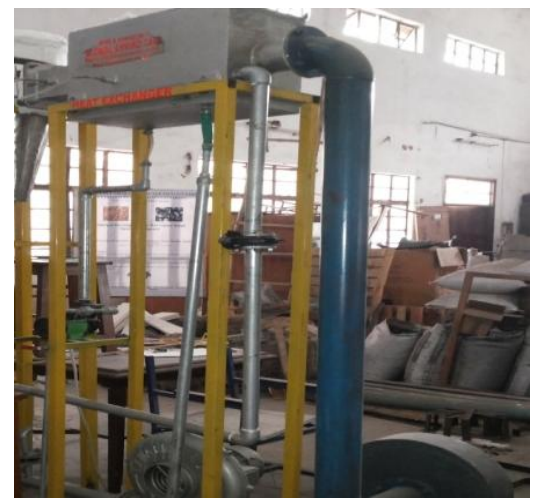

Fig. 3. Actual picture of flue gas cooler of experimental setup.

TABLE I: DIMENSION OF FLUE GAS COOLER AND OTHER PARAMETERS

\begin{tabular}{|l|l|l|}
\hline Description & $\begin{array}{l}\text { Numeric } \\
\text { Value }\end{array}$ & Units \\
\hline Dimensions $\left(1^{*} \mathrm{~b} * \mathrm{~h}\right)$ & $0.5 * 0.3 * 0.4$ & $\mathrm{~m}^{3}$ \\
\hline Water Flow Rate & $10-15$ & $\begin{array}{l}\text { Litre per minute } \\
(\mathrm{lpm})\end{array}$ \\
\hline Inlet water temperature & 303 & $\mathrm{~K}$ \\
\hline Outlet water temperature & 313 & $\mathrm{~K}$ \\
\hline Inlet flue gas temperature & $673-523$ & $\mathrm{~K}$ \\
\hline Outlet flue gas temperature & $423-523$ & $\mathrm{~K}$ \\
\hline Atmospheric pressure & 1 & $\mathrm{bar}$ \\
\hline Water Pump Capacity & 0.5 & $\mathrm{HP}$ \\
\hline Pipe Diameter & 0.5 & inch \\
\hline Pipe Material & Copper & \multicolumn{2}{|l|}{} \\
\hline
\end{tabular}

\section{CFD MODELLING}

The conservation equations involved in this study are given as follows. The brief description is as follows.

Mass Conservation equation for gas phase

$$
\frac{\partial}{\partial t}\left(f_{g} \rho_{g}\right)+\nabla \cdot f_{g} \rho_{g} v_{g}=0
$$

Mass conservation for solid phase

$$
\frac{\partial}{\partial t}\left(f_{s} \rho_{s}\right)+\nabla \cdot f_{s} \rho_{s} v_{s}=0
$$

Momentum equation for gas phase

$$
\begin{gathered}
\frac{\partial}{\partial t}\left(f_{g} \rho_{g} v_{g}\right)+\nabla \cdot f_{g} \rho_{g} v_{g} v_{g}=-f_{g} \nabla \cdot T_{g}^{e f}+f_{g} \rho_{g} g-\nabla p \\
+\mathrm{F}_{\mathrm{res}}
\end{gathered}
$$

Momentum conservation in solid phase:

$$
\frac{\partial}{\partial t}\left(f_{s} \rho_{s} v_{s}\right)+\nabla \cdot f_{s} \rho_{s} v_{s} v_{s}=f_{s} \rho_{s} g-\mathrm{F}_{\mathrm{res}}
$$

Energy conservation in the gas phase:

$$
\frac{\partial}{\partial t}\left(f_{g} \rho_{g} v_{g} C_{p g} T_{g}\right)+\nabla \cdot f_{g} \rho_{g} v_{g} C_{p g} T_{g}=-f_{g} \nabla \cdot q_{g}^{e f}+f_{g} q_{g s}
$$

Energy conservation in the solid phase:

$$
\frac{\partial}{\partial t}\left(f_{s} \rho_{s} v_{s} C_{p s} T_{s}\right)+\nabla \cdot f_{s} \rho_{s} v_{s} C_{p s} T_{s}=f_{s} q_{g s}
$$

Constitutive equations:

$$
T_{g}^{e f}=-2 \mu^{e f} D_{g}
$$

The deformation rate is given as:

$$
\begin{gathered}
D_{g}=1 / 2\left[\nabla v_{g}+\nabla v_{g}^{T}\right] \\
\mu_{e f}=\mu_{g}+\mu^{(t)}
\end{gathered}
$$

A correlation for turbulent viscosity is given as follows:

$$
\mu^{(t)}=\rho_{g k_{g}^{1 / 2}} \mathrm{D}_{\mathrm{h}} / 10
$$

For particles in flue gas discrete particle model is used. The reasons for choosing standard Lagrangian Model for dispersed phase is due to limited computational power available. The particle trajectory can be predicted for the $i x(\mathrm{i}$ $=1,2,3$ for three dimensions) direction in Cartesian coordinates by [6]:

\begin{tabular}{|c|c|}
\hline Parameter & Details \\
\hline No. of Cells used & 900218 \\
\hline Type of Cells Used & Hexahedral and Triangular \\
\hline Multiphase Model & Eulerian Lagrangian \\
\hline Fuel Feed rate & $10-15 \mathrm{~kg} / \mathrm{hr}$ \\
\hline Oxygen Fed rate & $10 \mathrm{Kg} / \mathrm{hr}$ \\
\hline Amount Air Fed & $40 \mathrm{~kg} / \mathrm{hr}$ \\
\hline Pressure & Atmospheric \\
\hline Convergence Criteria & 0.0001 \\
\hline $\begin{array}{l}\text { Pressure velocity } \\
\text { coupling }\end{array}$ & $\begin{array}{l}\text { Phase coupled } \\
\text { SIMPLE }\end{array}$ \\
\hline Air inlet velocity & $2-8 \mathrm{~m} / \mathrm{s}$ \\
\hline Particles & $\begin{array}{l}\text { Ash from biomass and } \\
\text { coal[Average particle size } \\
\text { of }[0.1-0.45 \mathrm{~mm}]]\end{array}$ \\
\hline $\begin{array}{l}\text { Under } \\
\text { factors }\end{array}$ & $\begin{array}{l}\text { Pressure: } 0.1 \text {, Density: } 1 \text {, } \\
\text { Body Forces: 1, } 1 \text {, } \\
\text { Momentum: } 0.3 \text {, Energy: } \\
0.5 \text {, DPM: } 0.3\end{array}$ \\
\hline
\end{tabular}

$$
\frac{d^{2} x_{i}}{d t^{2}}=F_{D}\left(v_{i}-v_{p, i}\right)+g x_{i} \frac{\left(\rho_{p}-\rho\right)}{\rho_{p}}+F_{x_{i}}
$$

where $F_{x i}$ is the additional force, $F_{D}\left(v_{i}-v_{p, i}\right)$ is the drag force per unit particle mass and

$$
F_{D}=\frac{18 \mu}{\rho_{p} d_{p}^{2}} \frac{C_{D} \operatorname{Re}}{24}
$$

The details of CFD model is given elsewhere in Ansys Fluent User Guide [6]. The details of boundary conditions and solution methodology can be referred from Table II.

TABLE II: BOUNDARY CONDITIONS AND OTHER SIMULATION DETAILS

The numerical simulation was carried out at inlet air velocity of $2 \mathrm{~m} / \mathrm{s}$ and particle concentration diameter varies from 0.1 to $0.45 \mathrm{~mm}$ at $623 \mathrm{~K}$. The boundary conditions are chosen from experimental details as mentioned in Table II. 


\section{RESUlTS AND DISCUSSION}

The CFD model is solved using commercial Software Ansys Fluent. The geometrical domain is formed in Solid Works. The simulations were performed in Ansys Fluent commercial software. The simulation was run on workstation, T1700, xenon quad core processor, $3.7 \mathrm{mz}, 32 \mathrm{~GB}$ Ram. The simulation is run for approximately six hours for 5000 iterations for each individual result. The mesh used for CFD simulation is shown in Fig. 4. It consists of primarily hexahedral and pyramid elements.

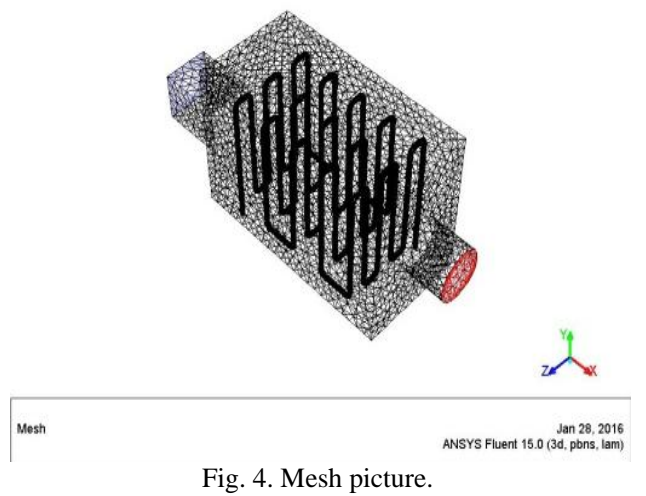

Fig. 5 shows the velocity profiles in flue gas cooler. The velocity contours are formed through commercial software. The velocity near the entry is higher and its decreases as it contacts with walls of tubes and duct. The velocity is higher at the exit pipe as shown in Fig. 5. It is higher because of fact that cross-sectional area is decreasing at the exit. Fig. 6 shows the velocity vectors in flue gas cooler. Fig. 6 also shows some of reverse flow occurs near the walls of flue gas cooler. It occurs because of continuously sucking the flue gas at high velocity by exhaust fan and some abnormalities in flow due to fouling. Due to fouling there is layer of deposition of ash on pipes. This layer is of uneven thickness causing abnormalities in flow.
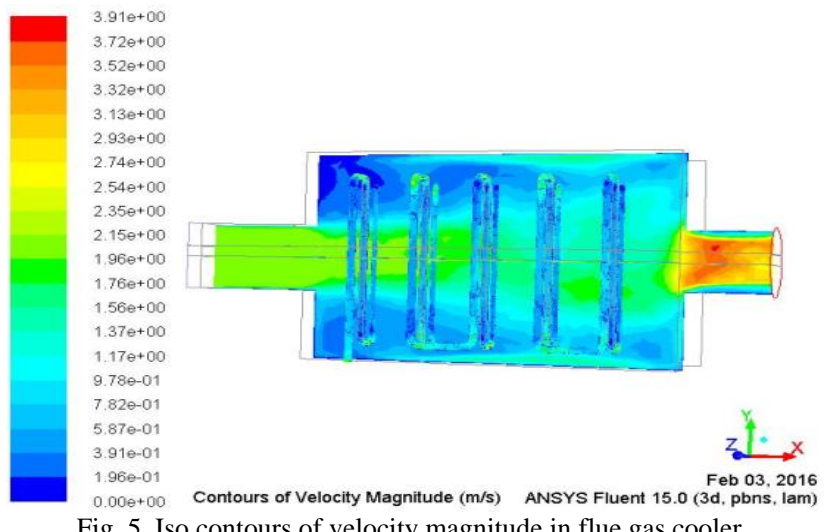

Fig. 5. Iso contours of velocity magnitude in flue gas cooler.

Fig. 7 shows the temperature contours in in flue gas cooler Inside the cooler it varies from 400 to $523 \mathrm{~K}$. At the exit the temperature is higher. It is because of high velocity few ash particles are carried along with flue gas and could not get enough time for cooling. The temperature inside the copper pipe is constant as cooling is done constant through continuous supply of water 0.5 HP motor. Fig 8,9 shows the flow of ash particles inside flue gas coolers. As shown in Fig. 9 the heavier particle will stay inside cooler and are removed through lower opening in cooler. Whereas lighter particles are drifted towards exit. Due to space limitation only two particles are shown. The average size of ash due to fine coal is $0.1 \mathrm{~mm}$ and average size due to coarse biomass is $0.45 \mathrm{~mm}$. Due to size of ash the fouling conditions prevails in flue gas cooler. Flue gas exit temperature versus ash particle size is shown in fig. 10 . Flue gas temperature increases by $60 \mathrm{~K}$. It is shown in Fig. 10. This is because increase in size of ash causing fouling of heat exchanger tubes which in turns decreases the effectiveness of flue gas cooler. These results are also compared with respect to CFD model. Experimental measurements were also taken and validated with CFD model.

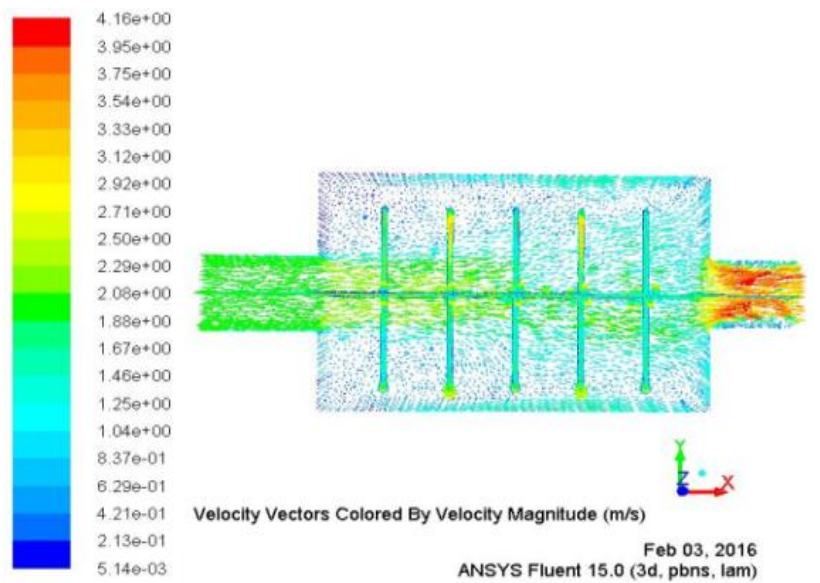

Fig. 6. Velocity vectors in flue gas coolers.
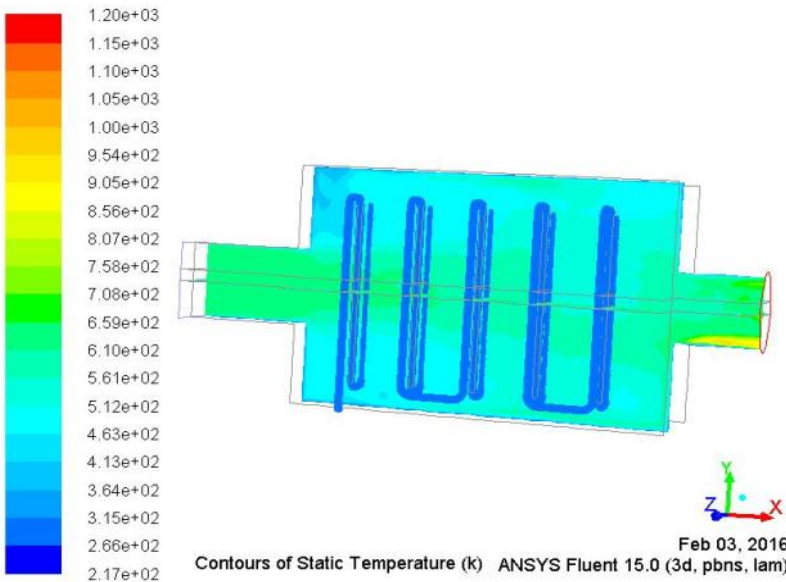

Fig. 7. Temperature contours in flue gas cooler.
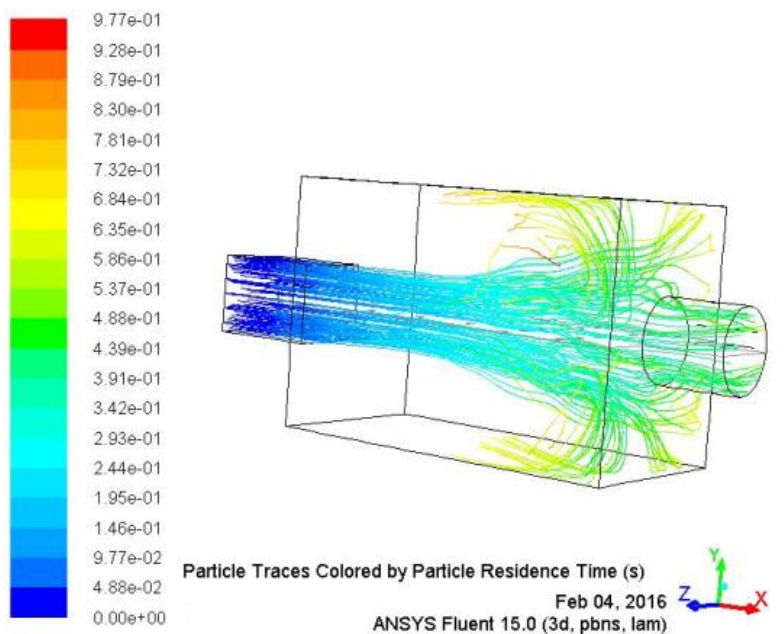

Fig. 8. Particle size of $0.1 \mathrm{~mm}$ ash particles.

Table III shows the comparison of overall heat transfer 
coefficients between CFD model and experimental setup. The overall heat transfer coefficients are perfectly matching with in permissible limits. The detailed discussion of all of ash particles and many more results are beyond the scope of this paper.

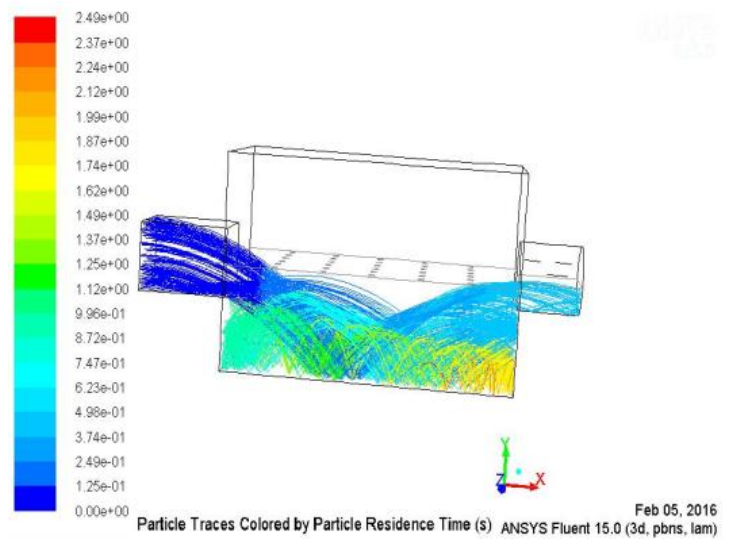

Fig. 9. Particle size of $0.45 \mathrm{~mm}$ ash particles.

TABLE III: OVERALL HEAT TRANSFER COEFFICIENTS (CFD MODEL AND

\begin{tabular}{|l|l|l|l|}
\hline \multicolumn{1}{|c}{ EXPERIMENTAL) \{ASH PARTICLE SIZE 0.1\} } \\
\hline $\begin{array}{l}\text { Overall Heat } \\
\text { Transfer } \\
\text { Coefficients at } \\
\text { Pipes(Copper) }\end{array}$ & 880 & 890 & Unit \\
\hline $\begin{array}{l}\text { Overall Heat } \\
\text { Transfer } \\
\text { Coefficients are } \\
\text { Walls(Mild Steel) }\end{array}$ & 780 & 800 & $\mathrm{~W} / \mathrm{m}^{2} \mathrm{~K}$ \\
\hline
\end{tabular}

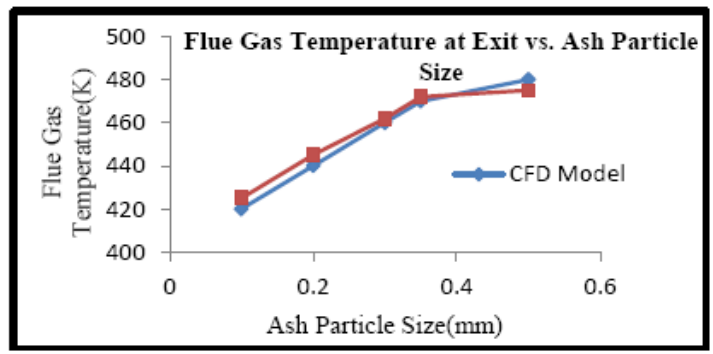

Fig. 10. Figure flue gas temperature vs. ash particle size.

\section{CONCLUSION}

Flue gas coolers are important equipment in many of industrial process. CFD modeling is correctly predicting the velocity and temperature contours inside flue gas cooler. CFD methodology is capable to predict the effectiveness of flue gas cooler with reasonable accuracy. From the study following more points can be concluded.

- The velocity range predicted by CFD model and measurement is varying from 2 to $7 \mathrm{~m} / \mathrm{s}$.

- The Temperature range predicted by CFD model and measurement is varying from 400 to $620 \mathrm{~K}$.

- The stay of bigger ash particles (coarse biomass) in ash cooler is higher in flue gas cooler as compare to fine coal.

\section{NOMENCLATURE}

$C_{p g}=$ specific heat of gas, $\mathrm{J} / \mathrm{kg} \mathrm{K}$

$C_{p s}=$ specific heat of solid particle, $\mathrm{J} / \mathrm{kg} \mathrm{K}$

$D_{g}=$ deformation rate factor of gas, $\mathrm{m}^{2} / \mathrm{s}$

$f_{g}=$ volumetric fraction of gas

$f_{s}=$ volumetric fraction of solid particles

$\mathrm{F}_{\text {res }}=$ Resistive force, $\mathrm{N}$

$\mathrm{g}=$ gravitational acceleration, $\mathrm{m} / \mathrm{s}^{2}$

$\mathrm{k}_{\mathrm{g}}=$ turbulent kinetic energy of gas, $\mathrm{J}$

$\nabla p=$ pressure drop, $\mathrm{Pa}$

$q_{g}^{e f}=$ Effective heat transfer rate of gas, $\mathrm{J}$

$T_{s}=$ Temperature of solid particle, $\mathrm{K}$

$T_{g}^{e f}=$ effective shear stress of gas, $\mathrm{N} / \mathrm{m}^{2}$

$T_{g}^{e f}=$ Effective shear stress in gas, $\mathrm{N} / \mathrm{m}^{2}$

$T_{g}=$ Temperature of gas, $\mathrm{K}$

$v_{s}=$ Velocity of solid particles, $\mathrm{m} / \mathrm{s}$

$v_{g}=$ Velocity of gas, $\mathrm{m} / \mathrm{s}$

$\rho_{s}=$ density of solid particles, $\mathrm{kg} / \mathrm{m}^{3}$

$\rho_{g}=$ density of gas, $\mathrm{kg} / \mathrm{m}^{3}$

$\mu_{e f}=$ effective viscosity, $\mathrm{Nm}^{-1} \mathrm{~s}^{-1}$

$\mu_{g}=$ viscosity of gas, $\mathrm{Nm}^{-1} \mathrm{~s}^{-1}$

$\mu^{(t)}=$ turbulent viscosity, $\mathrm{Nm}^{-1} \mathrm{~s}^{-1}$

\section{ACKNOWLEDGMENT}

Author is thankful to Department of Science and Technology, New Delhi, India for providing financial grant for conducting research. Author is also thankful to BITS pilani, Pilani Campus, India and DST, New Delhi India for boarding, lodging and registration fees expenses.

\section{REFERENCES}

[1] V. Westergaard and J. A. Fife, "Flue gas cooling," in Proc. National Incinerator Conference, pp. 170-180, 1964.

[2] H. M. Kvamsdal, G. Haugen, and H. F. Svendsen, "Flue-gas cooling in post-combustion capture plants," Chemical Engineering Research and Design, vol. 89, issue 9, pp. 1544-1552, 2011.

[3] J.-Q. Gao and S.-D. Sun, "The simulation model of the exhaust flue gas cooler in 300MW oxy-coal fired boiler," in Proc. 5th International Conference on Information Engineering for Mechanics and Materials, Atlantis Press, pp. 1060-1064, 2015.

[4] N. Goel, "Design and performance analyses of condensing heat exchangers for recovering water and waste heat from flue gas," Thesis and Dissertation, Lehigh University, 2012.

[5] S. Maalouf, E. B. Ksayer, and D. Clodic, "Investigation of direct contact condensation for wet flue-gas waste heat recovery using organic rankine cycle," Energy Conversion and Management, vol. 107, pp. 96-102, 2016.

[6] Ansys Fluent 2014 User's Guide, Fluent Incorporated, Centerra Resource Park, 10 Cavendish Court, Lebanon NH 03766, 2014.

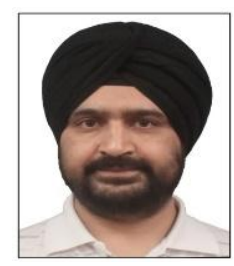

Ravi Inder Singh was born on $18^{\text {th }}$ Oct 1979 . He completed his $\mathrm{PhD}$ in thermal engineering in year 2010 from Thapar University Patiala, India. He has more than thirteen years of experience in teaching and research. He has completed post doctoral fellowship in chemical engineering in Abo Academy University Finland and Petroleum Institute UAE. He completed many research projects in field of thermal engineering. He has more than fifty papers in reputed international Journals and Conferences. He area of research is thermal and energy engineerings. 